Case Report

\title{
Atypical vascular proliferation after radiation for breast carcinoma Atypical vascular proliferation
}

\begin{abstract}
We present the case of a 51-year-old Caucasian woman with a history of stage II invasive ductal carcinoma of the left breast that presented atypical erythematous lesions of three months history after radiation two years before for a breast carcinoma. Biopsy was done to distinguish a benign lesion from the main differential diagnosis, which is angiosarcoma. Distinguishing post-radiation benign from malignant vascular lesions can be challenging because they share overlapping clinical and histopathologic features. Thus, any vascular lesion that occurs in a previously irradiated skin should be excised completely with tumor-free margins and examined histologically. Prolonged follow-ups after radiation should be carried on in order to be aware that a lesion in the beginning, which was benign, could be transformed into post radiation angiosarcoma further on in time. There is some evidence that they represent a precursor to radiationinduced angiosarcoma.
\end{abstract}

Keywords: atypical vascular proliferation, post radiation vascular proliferation, atypical proliferation, angiosarcoma post radiation
Volume 2 Issue 4 - 2018

\author{
Ruiz Beguerie Julieta,' Fernandez Julia,' Anaya \\ Javier ${ }^{2}$ \\ 'Department of Dermatology,Austral University Hospital, \\ Argentina \\ ${ }^{2}$ Department of Pathology, Austral University Hospital, Argentina
}

Correspondence: Julieta, Ruiz Beguerie, Dermatology Department, Austral University Hospital, Av Peron I500, Derqui, Buenos Aires, Argentina, Email jruiz@cas.austral.edu.ar

Received: June 21, 2018 | Published: July 27, 2018

\section{Case history}

A female patient of 51 years of age consulted in March 2018 for asymptomatic, recurrent and autoinvolutive erythematous papules of $4 \mathrm{~mm}$ in the left breast of 3months of evolution (Figures 1-3). Each lesion lasted a week. The patient was in oncological follow-up for left breast cancer of invasive ductal type diagnosed in 2016. She underwent quadrantectomy, axillary emptying and adjuvant chemotherapy with 4cycles of atracyclines (cyclophosphamide $1000 \mathrm{mg}$ and doxorubucine $100 \mathrm{mg}$ ) and 12 weeks of paclitaxel $80 \mathrm{mg} / \mathrm{m}^{2} /$ week. Additionally, they performed three-dimensional radiotherapy (RT) from July to October 2016. Then she continued on tamoxifen orally until today. With presumptive diagnoses of atypical vascular proliferation versus angiosarcoma versus cutaneous metastases, a punch biopsy was done of the most infiltrated lesion. The histology showed the presence in the reticular dermis of some irregular vascular channels that dissected the collagen, upholstered by flat endothelial cells or cuboids, without evidence of significant cytological atypia or mitosis. Focal erythrocyte extravasation coexisted (Figure 4). In the immunohisto chemistry, she had CD34 negative in the endothelium of the vascular channels, CK AE1 and AE3 and CK 7 negative for neoplastic cells and CD 68 positive in macrophage isolates (Figure 5). These changes were compatible with an atypical vascular lesion .

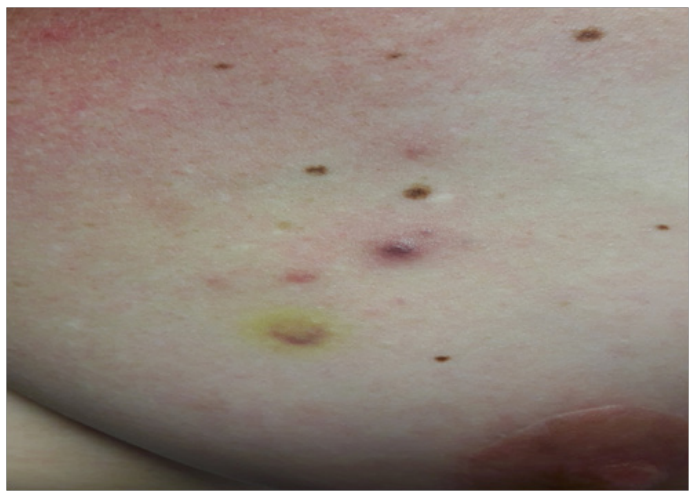

Figure I Hard erythematous papules of $4 \mathrm{~mm}$ on the skin of the left breast.

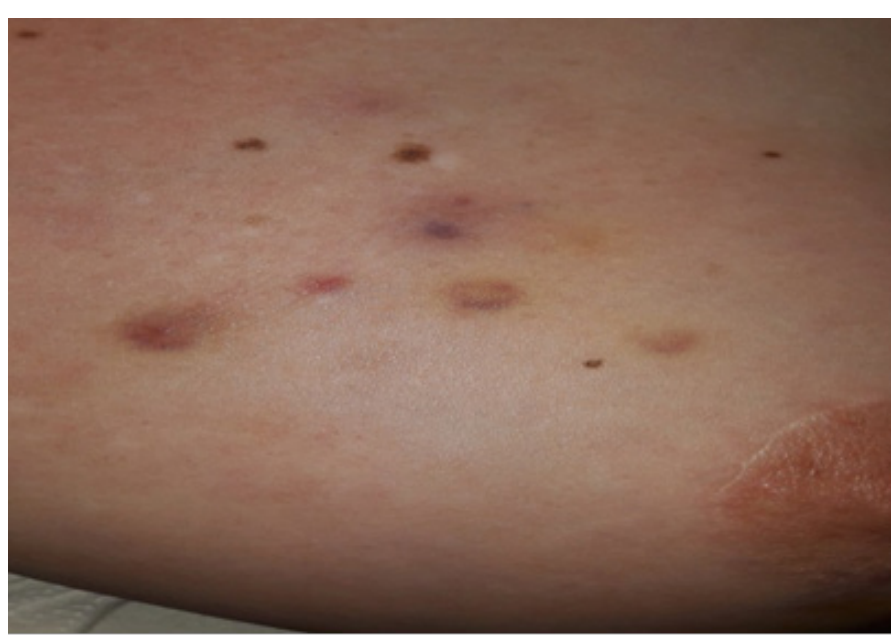

Figure 2 Hard papules and violaceous macule on the left breast.

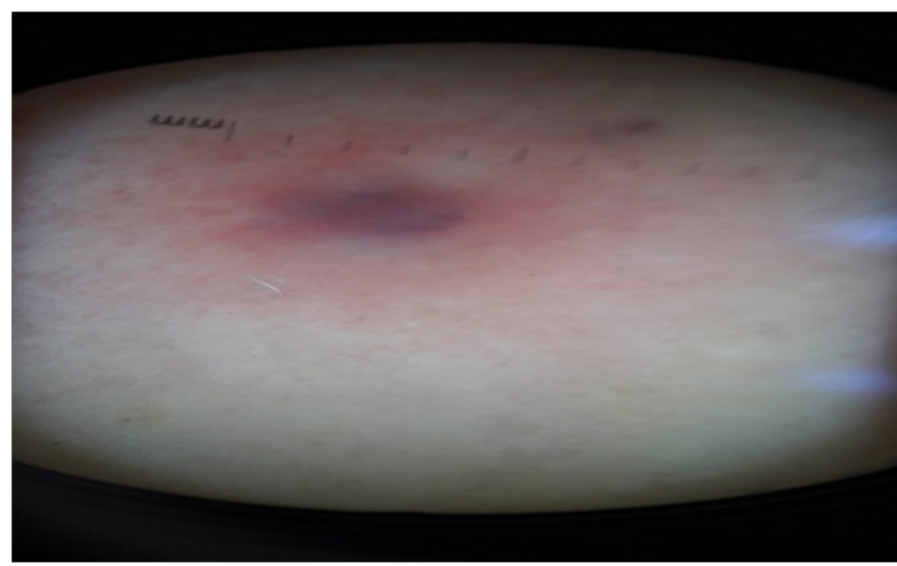

Figure 3 Dermoscopy of the vascular lesion on the left breast. 


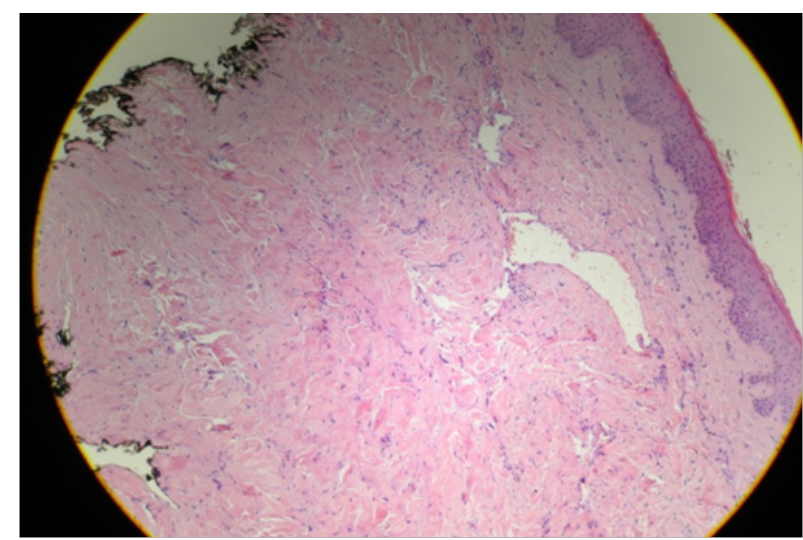

Figure 4 Irregular vascular channels dissecting the collagen, and flat endothelial cells without evidence of significant cytological atypia or mitosis.

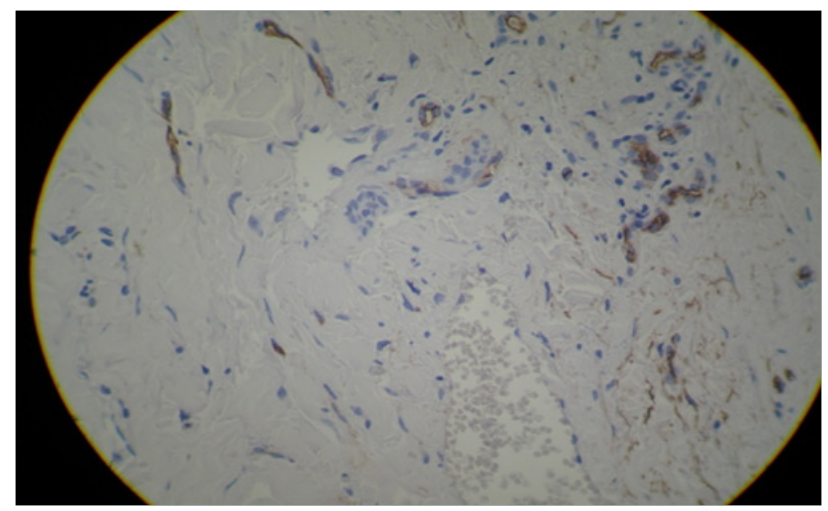

Figure 5 Immunohistochemistry CD68 positive for macrophages.

\section{Introduction}

Despite the widespread use of radiation therapy to treat breast carcinoma, atypical vascular proliferation and angiosarcomas arising in the field of radiation therapy are rare. ${ }^{1}$ Radiotherapy has short and long side effects. Months or even years later it may appear very tiny broken veins or they may grow on the surface of the treated area: telangiectasias. Vascular Tumors appear in the long run after radiotherapy. Postradiation Vascular Tumors have been described as two types

\section{i. Post-radiation angiosarcoma \\ ii. Atypical vascular lesions}

The post-radiation angiosarcoma is the malignant variant with significant mortality, and atypical vascular lesions develop in a benign manner. ${ }^{2}$ Moreover, it has been suggested that some forms of angiosarcoma have arisen from atypical vascular lesions after many years. ${ }^{3-4}$ There are no distinct clinical or histologic differences between primary and postradiation angiosarcomas..$^{5-7}$ Investigations showed a substantial time difference between when patients presented with atypical vascular lesions (AVL) (median 3.5years) and cutaneous angiosarcoma, (median 6years) postradiation., ${ }^{3,89}$. They found 2 histological types; a lymphatic type (LT) in most cases and a vascular type (VT). LT AVLs consisted of thin-walled, variably anastomosing lymphatic vessels confined to the superficial dermis. The vascular type consisted of small, irregularly dispersed, often blood-filled, pericyteinvested, capillary-sized vessels involving the superficial or deep dermis. There seems to be an association of AVL with angiosarcoma, hence, VT AVLs could be a precursor. ${ }^{10}$ Angiosarcomas presented as larger lesions (median, $7.5 \mathrm{~cm}$ ) compared with AVLs (median, $0.5 \mathrm{~cm}$ ) but most importantly the time interval from radiation is significantly shorter for the development of AVL. ${ }^{11}$

\section{Discussion}

For some authors they might be the same pathology in the spectrum with different period of appearance after radiation for cancer. ${ }^{3,12} \mathrm{We}$ showed this case to increase awareness of the difficulty in making the distinction of vascular atypical proliferation from more serious diagnosis and the importance of the follow up to be alert for the conversion to angiosarcoma. Currently there is some evidence that atypical vascular proliferation although considered a benign entity, represent a precursor to radiation-induced angiosarcoma. Concerning current data of these entities we recommend complete excision with free surgical margins and close follow up. ${ }^{13}$

\section{Acknowledgements}

None.

\section{Conflict of interest}

Author declares that there is no conflict of interest.

\section{References}

1. Mudaliar KM, Borrowdale R, Mehrotra S. Post-radiation Atypical Vascular Lesion/Angiosarcoma Arising in the Larynx. Head and Neck Pathology. 2014;8(3):359-363.

2. Sadick NS, Makino Y. Selective electro-thermolysis in aesthetic medicine: a review. Lasers Surg Med. 2004;34(2):91-97.

3. Losch A, Chilek KD, Zirwas MJ. Post Radiation Atypical Vascular Proliferation Mimicking Angiosarcoma Eight Months Following Breastconserving Therapy for Breast Carcinoma. J Clin Aesthet Dermatol. $2011 ; 4(4): 47-48$.

4. Fraga Guedes C, Gobbi H, Mastropasqua MG, et al. Clinicopathological and immunohistochemical study of 30 cases of post-radiation atypicalvascular lesion of the breast. Breast Cancer Res Treat. 2014;146(2):347-354.

5. Wang XY, Jakowski J, Tawfik OW, et al. Angiosarcoma of the breast: a clinicopathologic analysis of cases from the last 10 years. Ann Diagn Pathol. 2009;13(3):147-150.

6. Mattoch IW, Robbins JB, Kempson RL, et al. Post-radiotherapy vascular proliferations in mammary skin: a clinicopathologic study of 11 cases. $J$ Am Acad Dermatol. 2007;57(1):126-133.

7. Fineberg S, Rosen PP. Cutaneous angiosarcoma and atypical vascular lesions of the skin and breast after radiation therapy for breast carcinoma. Am J Clin Pathol. 1994;102(6):757-763.

8. Trelles MA, Allones I, Velez M. Nonablative facial skin photorejuvenation with an intense pulsed light system and adjunctive epidermal care. Lasers Med Sci. 2003;18(2):104-111.

9. Bogle MA, Ubelhoer N, Weiss RA, et al. Evaluation of the multiple pass, low fluence algorithm for radiofrequency tightening of the lower face. Lasers Surg Med. 2007;39(3):210-217.

10. Patton KT, Deyrup AT, Weiss SW. Atypical vascular lesions after surgery and radiation of the breast: a clinicopathologic study of 32 cases analyzing histologic heterogeneity and association with angiosarcoma. Am J Surg Pathol. 2008;32(6):943-950. 
11. Brenn T, Fletcher CD. Radiation-associated cutaneous atypical vascular lesions and angiosarcoma: clinicopathologic analysis of 42 cases. Am J Surg Pathol. 2005;29(8):983-996.

12. Suarez A, Johnson-Jahangir H, Desman G, et al. Post-radiation atypical vascular proliferation on the head of a young woman: a diagnostic challenge. Dermatol Online J. 2015;16;21(6).pii:13030/qt8ww5p7d2.
13. Sisti A, Tassinari J, Cuomo R, et al. A case of extramammary inguinal Paget disease in a male patient: surgical treatment with an abdominal advancement cutaneous flap. Acta Biomed. 2017;28;88(1):79-81. 